\title{
Efficiency and Cost Effectiveness Analysis of Water Repelling Penetrants on Aged Masonry Structures
}

Jafar Al-Sharab ${ }^{1}$, Ronnie Abukhalaf ${ }^{1}$, Mary Strieglel $^{2}$, Jason Church ${ }^{2}$, Linda Strauss ${ }^{3}$, Devin Rye ${ }^{1}$ and Daniele Forero-Salcedo ${ }^{1}$

${ }^{1}$ Northwestern State University, Natchitoches, Louisiana, United States, ${ }^{2}$ National Center for Preservation Technology and Training, Natchitoches, Louisiana, United States, ${ }^{3}$ Alliance Compressers, Natchitoches, Louisiana, United States

The National Center for Preservation Technology and Training (NCPTT) is the US's federal branch that deals in preservation of historical monuments, artifacts and structures. NCPTT was established in 1994 and is based on the campus of Northwestern State University. One of the main objectives of the center is advancing preservation techniques. Aged, or low fire, brick has suffered critical damage from mortar repairs of Portland Cement in the US, specifically water damage as moisture cannot move equally through low fire brick and Portland Cement. Effects of such an intrusion of water include spalling, stains, efflorescence, algae growth, and a decrease in insulating properties. The best way to continue preservation is to block moisture from entering the brick or mortar by using a water repelling penetrant. This research will compare the most widely used penetrants on low-fire brick and determine which product is best for preserving the masonry brick structures. Water repelling abilities as well as water vapor permeability will be tested using RILEM tubes, a freeze/thaw chamber, as well as simple weight comparisons to determine water absorption. The aim of this study is to protect antique masonry structures from water damage using water repelling penetrants. Detailed characterizations techniques will be used in order to assess the optimum properties of the water repellent coatings and best adhesion conditions. The study will also touch on correlation between the cost-effectiveness and the performance of the water repellent products.

In this study low fire bricks were purchased and examined. A small wall with dimensions of $78.75^{\prime} 60.0$ $21.5 \mathrm{~cm}$, Figure 1, was constructed and placed in an open environment. The masonry units were laid in a bed of lime-based mortar to mimic the exact structure of the classical building. A closed wooden structure was built to protect the back of the wall while the front side is exposed to normal environmental effects, Figure 1. Humidity and temperature on the back of the wall was controlled using Arduino microcontroller.

Two different water repellent penetrants were tested in this study. Penetrant A was applied on half of the wall while penetrant B was applied into the other half of the constructed wall. After completely drying, the water penetrants were investigating for their performance. A standard ASTM tests [1,2] were used to assess the efficiency of the applied penetrants on the masonry wall.

Initial results show that penetrant A has better performance that penetrant B. In order to understand the interaction of the penetrants chemistries with the brick structure, chemical composition of the bricks was investigated. Figure 1 shows the chemical analysis of the low fire brick using XRF. Results show that the strongest peak is corresponding to Fe- $\mathrm{K}_{\mathrm{a} 1}$ as an indication of the majority of the sample consists of iron composite. The XRF doesn't have the capability to detect light elements such as carbon and oxygen. Therefore, team on this project will utilize other techniques such as EDX, XPS, and XRD for accurate detection and quantification of all elements/phases present in the brick composition.

This study is also concern about the cost-effectiveness of the water repellant. This study will assess the number of Classical/Neoclassical buildings in the USA and perform cost analysis to find the cost of such 
improvements to prevent any further damage and preserve the integrity of these buildings structure for many years to come.

Work is on progress to conduct a complete structural and chemical analysis of the samples using scanning electron microscope, FTIR, and XRD. Such analysis will help understanding the adhesion properties and may explain the significant difference between penetrants performance. In addition, the effect of exposure time to external environmental conditions will also be assessed and presented [3].

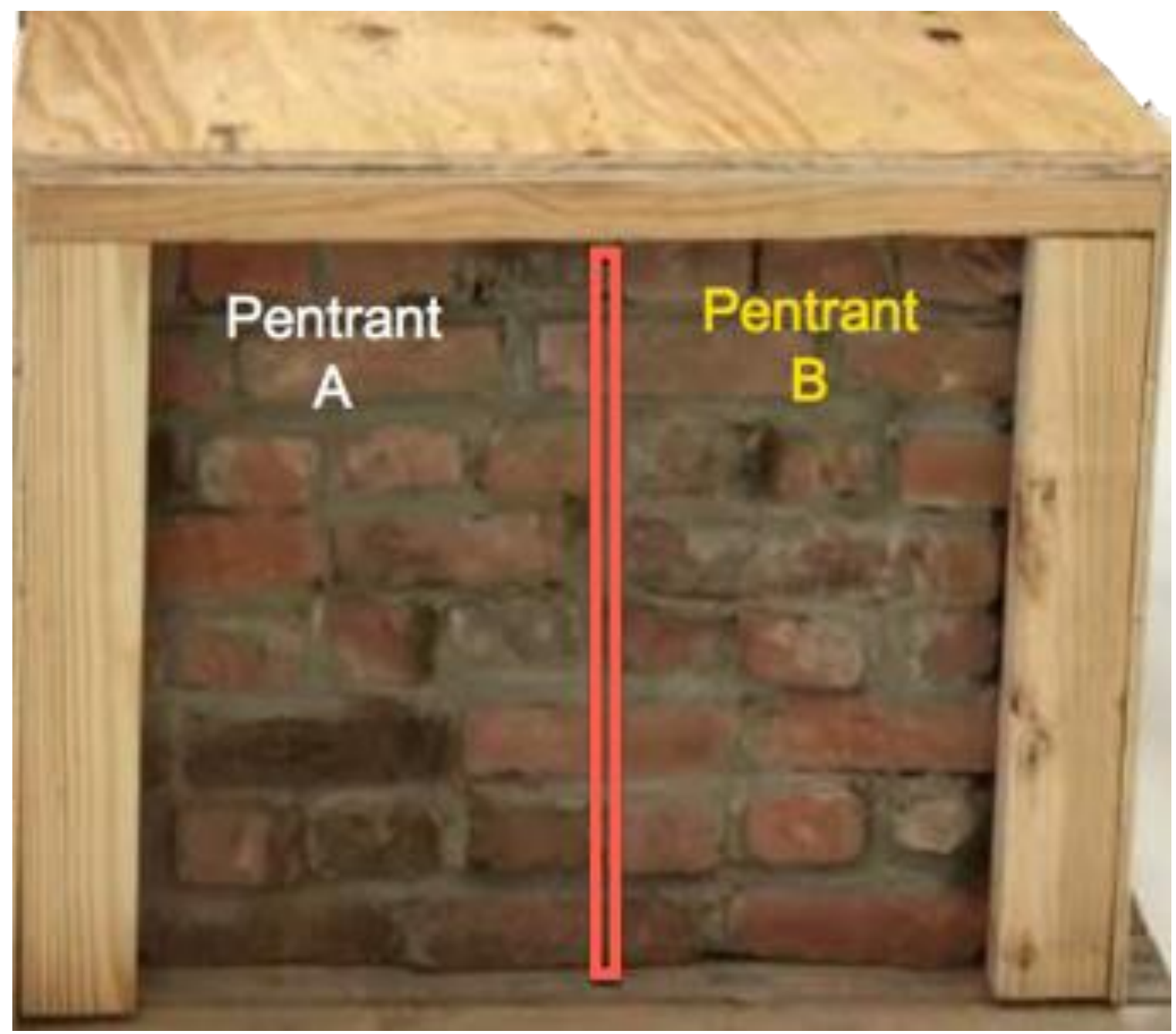

Figure 1. Constructed wall showing location of water repellant penetrants and protective wooden structure 


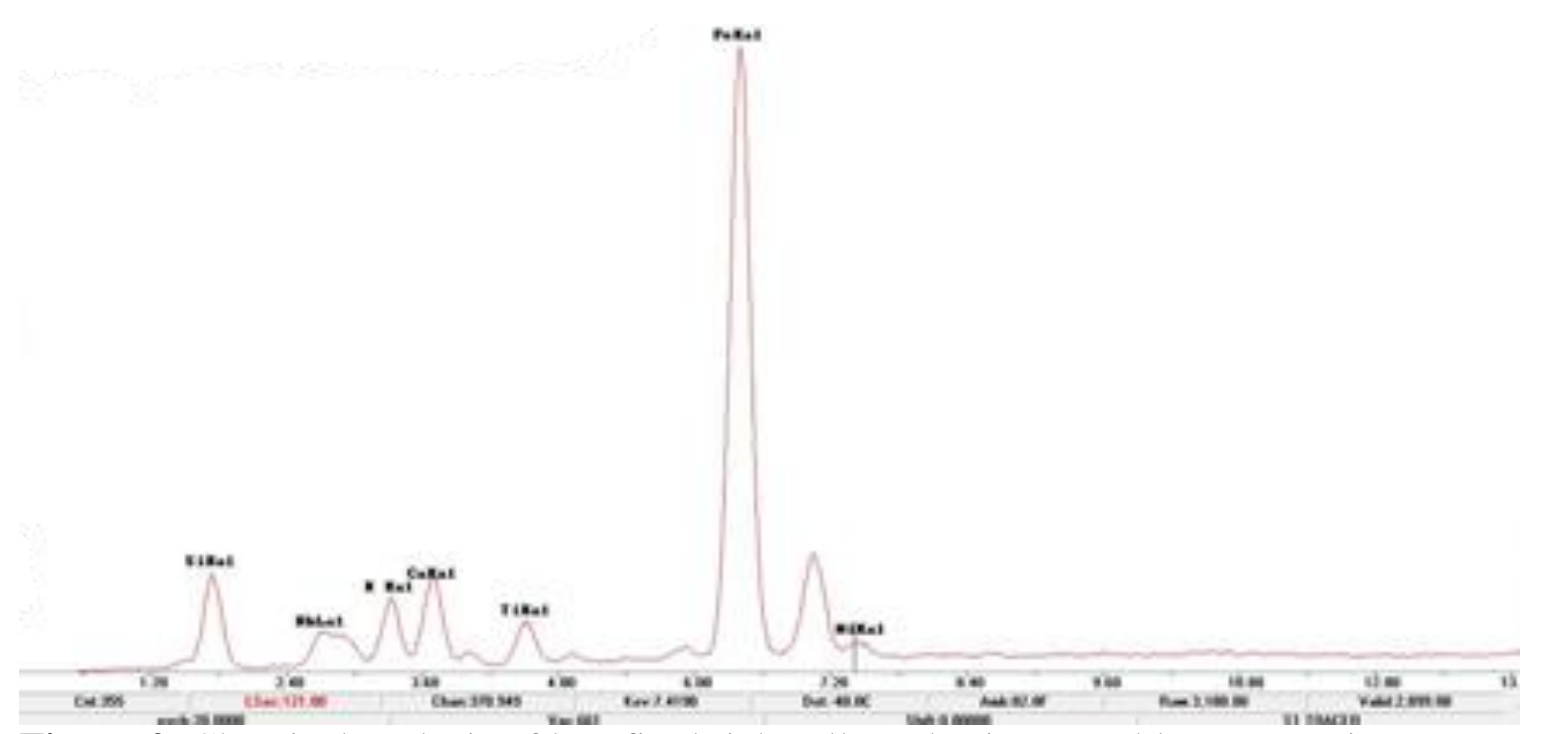

Figure 2. Chemical analysis of low fire brick collected using portable XRF equipment

\section{References}

[1] C20-00, "Standard Test Methods for Apparent Porosity, Water Adsorption, Apparent Specific Gravity, and Bulk Density of Burned Refractory Brick and Shapes by Boiling Water." ASTM, Conshohocken, PA, 2010.

[2] C67, "Standard Test Methods for Sampling and Testing Brick and Structural Clay Tile." ASTM, Conshohocken, PA, 2018.

[3] Support form Professional Products of Kansas and Prosoco is highly appreciated. 